\title{
Assessing Spillovers from Universities to Firms: Evidence from French firm-level data
}

Stéphanie Monjon (University College London and EUREQua, University of Paris I) Patrick Waelbroeck (ECARES, Free University Brussels)*

A pril 2003

\begin{abstract}
We assess the importance of information flows from universities to innovative firms and determine the relative contribution of formal collaboration and pure knowledge spillovers in this process. We find that spillovers provide the most benefit to firms that imitate existing technologies or those that are involved in incremental innovation, on the other hand highly innovative firms appear to derive most benefit from collaborative research with foreign universities. Indeed, highly innovative firms are at the frontier of the academic knowledge in their industry. Therefore, they do only marginally benefit from aggregate (or industry-wide) spillovers. They require new forms of academic knowledge that they acquire through formal cooperation with foreign universities.
\end{abstract}

Keywords: Innovation, spillovers, collaboration, universities

\footnotetext{
* We would like to thank seminar participants at the IJIO Workshop on the Economics of Intellectual Property at Universities for very helpful comments and suggestions. We are especially grateful to John Scott as well as two anonymous referees for very insightful comments and suggestions.
} 


\section{Introduction}

It has been clear over the last decades that the innovation process is not the result of isolated agents. Interactions among various agents of the economy have been acknowledged to be at the core of the process. Rosenberg and Nelson (1994) argue that universities, and more generally science and academic research are an important factor in the development of major innovations. This view is confirmed by several empirical studies that reveal the importance of universities in the innovation process (Jaffe, 1989; Berman, 1990; Mansfield, 1995). For instance, Mansfield (1995) finds that 10\% of the innovations under study ${ }^{1}$ could not have been developed without academic research, while Berman (1990) finds that direct industry funding of university research can be associated with subsequent increases in industry $R \& D$ expenditure.

Despite the fundamental importance of knowledge created in the universities, there is little direct evidence on the manner in which this knowledge is diffused among firms. We conjecture that knowledge emanating from universities is transmitted through formal cooperation or informally, through publications and discussions among scientists and engineers at conferences. In the former case, universities can more easily appropriate the rents resulting from innovative activity undertaken by their research partners. In the latter case, innovative firms benefit from pure knowledge spillovers. ${ }^{2}$

\footnotetext{
${ }^{1}$ His sample consists of 66 large firms from seven major manufacturing industries and 200 academic researchers.

2 Technological spillovers are defined as the non appropriable amount of knowledge that is created by an innovative firm. In the literature, a distinction is made between (i) knowledge spillovers, (ii) rent or 'market' spillovers, which arise when inputs are not priced at their true quality, and (iii) network spillovers, which arise when innovations are complementary to existing technologies. These spillovers can be transmitted by different mechanisms: their transmission can be voluntary or involuntary; they can be 'free' or acquired through a market. The extent to which knowledge is transferable depends on whether it is codified (patents) or tacit and informal, embodied or disembodied. While market spillovers are possible to measure (by quality-adjusted quantities of equipment exchanged between firms for instance), knowledge and network spillovers are difficult to assess. Indeed, they leave almost no trails and even when they do (in patent citations for instance), the quality of their measure is often poor. For a survey on technological spillovers, see G riliches (1992). It is also worth noting that the D asgupta and David (1994) argument that according to Mertonian norms of science, universities can benefit from diffusing knowledge via non-market channels is not pursued here.
} 
The goal of this article is to assess the importance of information flows from universities to innovative firms and to determine the relative contribution of formal collaboration and informal spillovers in this process. Our empirical analysis is based on a large sample of firms from the French Community Innovation Survey implemented in 1997 (henceforth CIS), which includes numerous proxies for knowledge transfers and R\&D collaboration.

There are many reasons to believe that there are substantial spillovers from universities to firms, most notably because universities pride themselves on having a culture of open "science" (see Poyago-Thetoky et al. (2002) and Siegel et al (2003)). Unfortunately, it is difficult to quantify such spillovers. ${ }^{3}$ The standard approach is to examine the geographical dimensions of these spillovers (Jaffe, 1989; Acs et al., 1992). However, this approach suffers from two drawbacks. First, spillovers that do not depend on the distance between universities and firms, such as journal publications or patents, are not captured. Second, previous studies do not control for the fact that some types of knowledge transfers are appropriable. As a consequence, the effects of universities on innovation identified in these studies can come from formal cooperation between universities and innovative firms, as well as knowledge spillovers. Two recent geographical studies attempt to overcome these limitations; Mowery and Ziedonis (2001) study the effect of the distance between an innovative firm and a university on licenses (market mechanism) and citations (spillover). They find that knowledge flows through market mechanisms tend to be more geographically concentrated than spillovers, a result challenged by Audretsch and Stephan (1996).

The literature on the origin and effects of information emerging from universities that does not rely on a measure of geographic proximity is scarce. Gibbons and Johnston (2000) find that the most important sources of academic knowledge come from the scientific literature and contacts with scientists. ${ }^{4}$ This result is also partially supported by Zucker, Darby and Armstrong (1998) and Torero (2000) who analyze the nature of external geographical effects from universities on nearby innovative firms in the biotechnology industry in California. Using a survey of 110 firms, the authors find that most technological

${ }^{3}$ Notice that this problem is not specific to the spillovers from universities.

4 The authors identify 887 units of information that are classified according to the content (academic, supplier, customers, ...) and the source (external to the firm, internal to the firm and personal). 
breakthroughs originate from firms with specific links with star scientists and not from general knowledge spillovers. However, it turns out that these apparently localized effects occur mainly through market exchange, as these scientists act as principals, employees or consultant for the innovative firms. Using survey data, Cohen and Walsh (2000) study the relationship between various measures of appropriability, information flows from rivals that lead to new projects (R\&D spillover) and $R \& D$ to sales ratio at the level of the industry. The authors report that information from universities and government laboratories do not appear to increase intra-industry R\&D information flows, public channels for accessing university research are associated with higher intra-industry spillovers.

The CIS that we use in this study has several unusual features. First, the survey inquires about the information sources that firms actually used in order to innovate. Most importantly, it contains information on whether a firm used knowledge emanating from universities to innovate, independently of the information transmission channel. Thus, we have a direct measure of knowledge flows, and do not need to rely on proxies, such as R\&D expenditures or patents, which are typically used in existing studies. Second, the survey also includes answers on the sources of national and international R\&D collaboration, including interactions with universities. In this way, we can decompose the information flows between universities and innovative firms into an appropriable part (formal collaboration) and pure knowledge spillovers. Finally, the CIS provides a measure of the degree of novelty of an innovation. Indeed, the survey informs us whether an innovation is only new to the firm that implements it, or new to the firm and to its market. ${ }^{5}$ In the latter case, firms will be called highly innovative and in the former case weakly innovative.

Making a distinction between these two types of innovators is important for at least three reasons. First, the existing literature analyses the role of informational networks on the innovation process at the level of an industry (Schrader, 1991 ; Appleyard, 1996). But, technological change within an industry relies on a great diversity of innovative behaviors. For instance, in France, the aeronautic and pharmaceutical industries are viewed as very innovative, but, within these industries, some firms are weakly innovative. Second, universities mainly conduct basic research and should play an important role in the development of radical innovations (Rosenberg and Nelson, 1994). Finally, there is no 
reason to believe that all innovative firms use the same information sources at the same intensity level. Indeed, the origin of spillovers could in principle differ according to the nature of the innovation.

We find that most benefits from contacts with universities and public research organizations come from formal collaboration. On the one hand, there is little evidence of direct spillovers from universities and, anyway, that they are much smaller than spillovers from customers and suppliers. Moreover, we find evidence that these spillovers are strongest among firms that imitate existing technologies. On the other hand, we find convincing evidence that formal cooperation with foreign universities can be associated with highly innovative firms. Our results contribute to the literature on the effect of universities on $R \& D$ and innovation. First, we improve on the study of Cohen and Walsh (2000) and Cohen et al. (2002) by making an ex plicit distinction between market and non-market information flows. Moreover, our survey includes a more detailed list of inter-industry information and collaboration sources. Our findings are also similar to those presented in the geographical study of Mowery and Ziedonis (2001). Again we do not rely on proxies for spillovers and knowledge flows through market mechanisms. In addition, we make a distinction between weakly and highly innovative firms. We find that formal collaborations with universities are not geographically confined, supporting arguments advanced by Audretsch and Stephan (1996).

The remainder of the article is organized as follows. In section 2, we describe the data set. Section 3 details the sequential model and the econometric methodology. Section 4 comments on the results. Finally, section 5 concludes the article

${ }^{5}$ However, this information is only provided for product innovations. 


\section{Data}

Our data come from three surveys. The main source is the Community Innovation Survey conducted in France in 1997, which provides information on the innovation process for the period 1994-1996. ${ }^{6}$ This survey inquires about the nature and the sources of the innovations made by a representative sample of French manufacturing firms. Firms are first asked whether they have innovated at least once during the period, distinguishing product and process innovations. This gives a direct measure of the innovative activity of a firm. Although answers to that question are sometimes subjective, they provide an interesting and different measure from traditional measures such as the average $R \& D$ in an industry or the patent activity of an innovative firm. These measures are also problematic as indicators of the innovative activity of a firm or of an industry. Indeed, $R \& D$ expenses do not necessarily lead to an innovation and even in this case, a firm might decide to keep its invention secret, or not commencialise the results of the research activity. ${ }^{7}$ We refer to a firm that answered yes to this first question as innovative. In the survey, 1644 firms innovated at least once during the period 1994-96: 184 only developed a new production process, 407 only launched a new product and 1053 implement both product and process innovations. ${ }^{8}$

Next, the survey asks innovative firms to specify if during the period they have introduced a new product that is not only new to the firm but also new to its market. We interpret a positive answer to question as indicating that the firm is highly innovative and a negative answer as indicating that the firm is weakly innovative and is catching up to more innovative firms. ${ }^{9} 1460$ firms reported that they had engaged in product innovation; 842 of these 1460 companies reported that they had introduced a new product on the market.

\footnotetext{
${ }^{6}$ In France, this survey has been conducted by the SESSI, which is a department of the French Ministry of the Economy and of the Industry in charge of industrial statistics and studies. For more information about this survey, see François and Favre (1998).

${ }^{7}$ See G riliches (1990) for a discussion about the measurement problems of innovation.

8 We can however not identify firms that both introduce radical and incremental innovations. However, we consider answers to this question as an indication of the strategy and the performance of the innovative firm. Moreover, although we have information on the profits from new products, we believe that it is a poor measure of the innovative performance of a firm as incremental innovations on a market with an important demand can generate substantial profits.

${ }^{9}$ Note that the survey covers a three-year period. Firms that only imitated existing technologies during this period can be considered as weakly innovative. Although this measure is far from being perfect, it still gives a good indication of the technological position of the firm and of its innovation strategy.
} 
Moreover, the survey asks innovative firms which informational sources have been used in the innovation process. These sources range from information specific to the firm to information available in the public domain. The nature of these sources is diverse since they correspond either to a single source or to a transmission channel. We refer to the former as direct spillovers and to the latter as indirect spillovers. The main argument for making this distinction is that it might happen that university knowledge has little marginal effect but still spills at the industry level through patent publications and technical journals or during scientific conferences and meetings. Using this data set, we can characterize the structure of the information network to which each firm belongs.

Table 1 presents the percentages of innovative firms that declared to have used a particular information source (firms declared having not used the source or used it on a low, average or high intensity level). Entries in columns 2-5 are computed using all innovative firms, while the last four columns correspond to highly innovative firms. Several stylized facts emerge from this table. First, it appears that innovative firms actively use internal information regardless of their innovation strategy. Indeed, whether firms introduce a new product on the market or imitate existing products, information is costly and takes time to assimilate and handle. Therefore, firms need internal capacities that result from $R \& D$, marketing or technology monitoring departments. Second, universities and public research organisations are used to a lesser extent in the innovation process. ${ }^{10}$ O nly $43 \%$ of innovative firms have at lest weakly used information from universities, a low figure compared to the other sources. Moreover, combining entries for universities and public research organizations shows that less than $7 \%$ of innovative firms have strongly used their knowledge, again a low figure compared to other sources.

10 Information form universities includes consultation of patents, technical articles, informal meeting and seminars, informal contact with scientists, research contracts and include many other sources that are not included in collaborations with universities. 


\section{Table 1. Information sources (percentage of firms having declared using the source, by intensity level)}

\begin{tabular}{|c|c|c|c|c|c|c|c|c|}
\hline & \multicolumn{4}{|c|}{$\begin{array}{l}\text { All innovative firms } \\
\text { (1644 obs.) }\end{array}$} & \multicolumn{4}{|c|}{$\begin{array}{l}\text { Highly innovative firms } \\
\text { (842 obs.) }\end{array}$} \\
\hline & $\begin{array}{l}\text { Not } \\
\text { used }\end{array}$ & Low & Average & High & $\begin{array}{l}\text { Not } \\
\text { used }\end{array}$ & Low & Average & High \\
\hline Internal sources & $7 \%$ & $9 \%$ & $29 \%$ & $55 \%$ & $5 \%$ & $8 \%$ & $28 \%$ & $60 \%$ \\
\hline Other firms of the group & $41 \%$ & $17 \%$ & $23 \%$ & $20 \%$ & $35 \%$ & $17 \%$ & $24 \%$ & $24 \%$ \\
\hline Competitors & $28 \%$ & $28 \%$ & $33 \%$ & $11 \%$ & $23 \%$ & $29 \%$ & $35 \%$ & $13 \%$ \\
\hline Customers & $17 \%$ & $16 \%$ & $33 \%$ & $34 \%$ & $12 \%$ & $15 \%$ & $33 \%$ & $40 \%$ \\
\hline Suppliers of equipment and software & $34 \%$ & $28 \%$ & $25 \%$ & $13 \%$ & $31 \%$ & $31 \%$ & $27 \%$ & $11 \%$ \\
\hline Suppliers of components and raw mat. & $31 \%$ & $31 \%$ & $26 \%$ & $11 \%$ & $26 \%$ & $34 \%$ & $27 \%$ & $13 \%$ \\
\hline Consulting market research firms & $68 \%$ & $22 \%$ & $8 \%$ & $2 \%$ & $64 \%$ & $26 \%$ & $9 \%$ & $2 \%$ \\
\hline Universities or establish. of higher edu. & $57 \%$ & $25 \%$ & $14 \%$ & $4 \%$ & $52 \%$ & $29 \%$ & $16 \%$ & $4 \%$ \\
\hline Public and non-profit research org. & $68 \%$ & $19 \%$ & $10 \%$ & $3 \%$ & $64 \%$ & $22 \%$ & $11 \%$ & $3 \%$ \\
\hline Publications of patents & $58 \%$ & $22 \%$ & $15 \%$ & $5 \%$ & $48 \%$ & $27 \%$ & $19 \%$ & $6 \%$ \\
\hline Technical journals and conferences & $39 \%$ & $30 \%$ & $26 \%$ & $6 \%$ & $32 \%$ & $33 \%$ & $29 \%$ & $7 \%$ \\
\hline Fairs and exhibitions & $24 \%$ & $30 \%$ & $36 \%$ & $10 \%$ & $19 \%$ & $32 \%$ & $37 \%$ & $13 \%$ \\
\hline
\end{tabular}

Finally, the survey also contains information on the sources of domestic and international R\&D collaboration, including universities. Collaboration is broadly defined as any type of monetary contractual agreement with the innovative firm. For universities, this includes licenses, research contracts, cross-licensing, research joint ventures, and human resources (e.g. scientists). Table 2 describes the origin and the nature of collaboration among innovative firms. Entries in each column give the percentages of firms that have cooperated with another firm or public organization by country. Cooperation is the most intensive with other agents from the same country (column France) and in the EU. In other words, many cooperation agreements are locally confined. Vertical cooperation (lines customers and 
suppliers) is extremely strong, while horizontal cooperation is used to a lesser extent (line competitors). Finally, universities and other public research organizations are often involved in cooperation agreements with innovative firms (last two lines). It is worth noting that contrary to information effectively used, collaborative agreements with research organizations are more common than with any other information sources.

\section{Table 2. Sources of cooperation (percentage of firms having declared having a cooperation agreement, by country of origin)}

\begin{tabular}{|c|c|c|c|c|c|c|c|c|}
\hline & \multicolumn{4}{|c|}{$\begin{array}{l}\text { All innovative firms } \\
\text { (1460 obs.) }\end{array}$} & \multicolumn{4}{|c|}{$\begin{array}{l}\text { Highly innovative firms } \\
\text { (842 obs.) }\end{array}$} \\
\hline & $\begin{array}{l}8 \\
\text { 胥 } \\
\text { 至 }\end{array}$ & p & 㐓 & $\begin{array}{l}\text { : } \\
\text { 票 }\end{array}$ & 惫 & P & 哥 & $\begin{array}{l}\text { ह } \\
\text { 跑 }\end{array}$ \\
\hline Other firms of the group & $14 \%$ & $14 \%$ & $9 \%$ & $2 \%$ & $17 \%$ & $18 \%$ & $11 \%$ & $3 \%$ \\
\hline Competitors & $3 \%$ & $4 \%$ & $2 \%$ & $1 \%$ & $4 \%$ & $5 \%$ & $2 \%$ & $2 \%$ \\
\hline Customers & $17 \%$ & $9 \%$ & $4 \%$ & $1 \%$ & $21 \%$ & $12 \%$ & $6 \%$ & $2 \%$ \\
\hline Suppliers of equipment and software & $11 \%$ & $6 \%$ & $3 \%$ & $1 \%$ & $14 \%$ & $7 \%$ & $4 \%$ & $1 \%$ \\
\hline Suppliers of components and raw mat. & $14 \%$ & $10 \%$ & $3 \%$ & $1 \%$ & $19 \%$ & $14 \%$ & $4 \%$ & $2 \%$ \\
\hline Consulting market research firms & $7 \%$ & $2 \%$ & $1 \%$ & $0 \%$ & $8 \%$ & $3 \%$ & $1 \%$ & $0 \%$ \\
\hline Universities or establ. of higher edu. & $18 \%$ & $5 \%$ & $2 \%$ & $0 \%$ & $21 \%$ & $7 \%$ & $2 \%$ & $0 \%$ \\
\hline Public and non-profit research org. & $13 \%$ & $2 \%$ & $1 \%$ & $0 \%$ & $15 \%$ & $3 \%$ & $1 \%$ & $0 \%$ \\
\hline
\end{tabular}

We complete our data set with information coming from the Annual census 1993 (in French, "E nquête A nnuelle d'entreprises"11) that provides accounting information about the line of business and sales at the firm level. ${ }^{12}$ These data enable to control for size and industry differences. These controls are necessary. Indeed, Link and Ress (1990) find that small entrepreneurial firms tend to benefit more than their established larger counterparts from

11 The «Enquête Annuelle d'Entreprises » (the industry census) is compulsory for all firms of 20 employees or more.

12 We have used data from 1993 to partially avoid simultaneity bias issues. 
university research spillovers. Moreover, large firms can better absorb fixed R\&D expenditures and collaboration expenses (legal and financial), a point stressed by Cohen and Levinthal (1989).

We also need to include proxies for market power and diversification as control variables in our econometric analysis. The market power of a firm has been constructed as the weighted average of market shares in the different sectors of activity where it operates. ${ }^{13}$ The diversification variable corresponds to the weighted average of the number of sectors in which a firm operates. The data used to construct these two variables come from a third survey, «l'E nquête A nnuelle d'E ntreprises par fractions 1993 » that provides information on total sales in each market (domestic or foreign) in which a firm operates. ${ }^{14}$ Combining these data sets provides a sample of 3193 French manufacturing firms with twenty or more employees.

\section{Methodology}

In innovation surveys (as a matter of fact in all Community Innovation Surveys in Europe), firms are usually first asked if they introduced a new product or a new process innovation. If they have answered yes to the first question, the survey inquires on the novelty of the new technology. We consider six different types of firms: $\left(a_{0}\right)$ the firm does not innovate, $\left(a_{1}\right)$ it only introduces a process innovation, $\left(\mathrm{a}_{2}\right)$ it only introduces an incremental product innovation, $\left(a_{3}\right)$ it introduces an incremental product and a process innovation, $\left(a_{4}\right)$ it only introduces a radical product innovation, $\left(a_{5}\right)$ it introduces a radical product and a process innovation.

13 For a detailed explanation of construction of the market power and diversification index, see Crépon et al. (1996).

14 This survey distinguishes among 300 industrial sectors. 


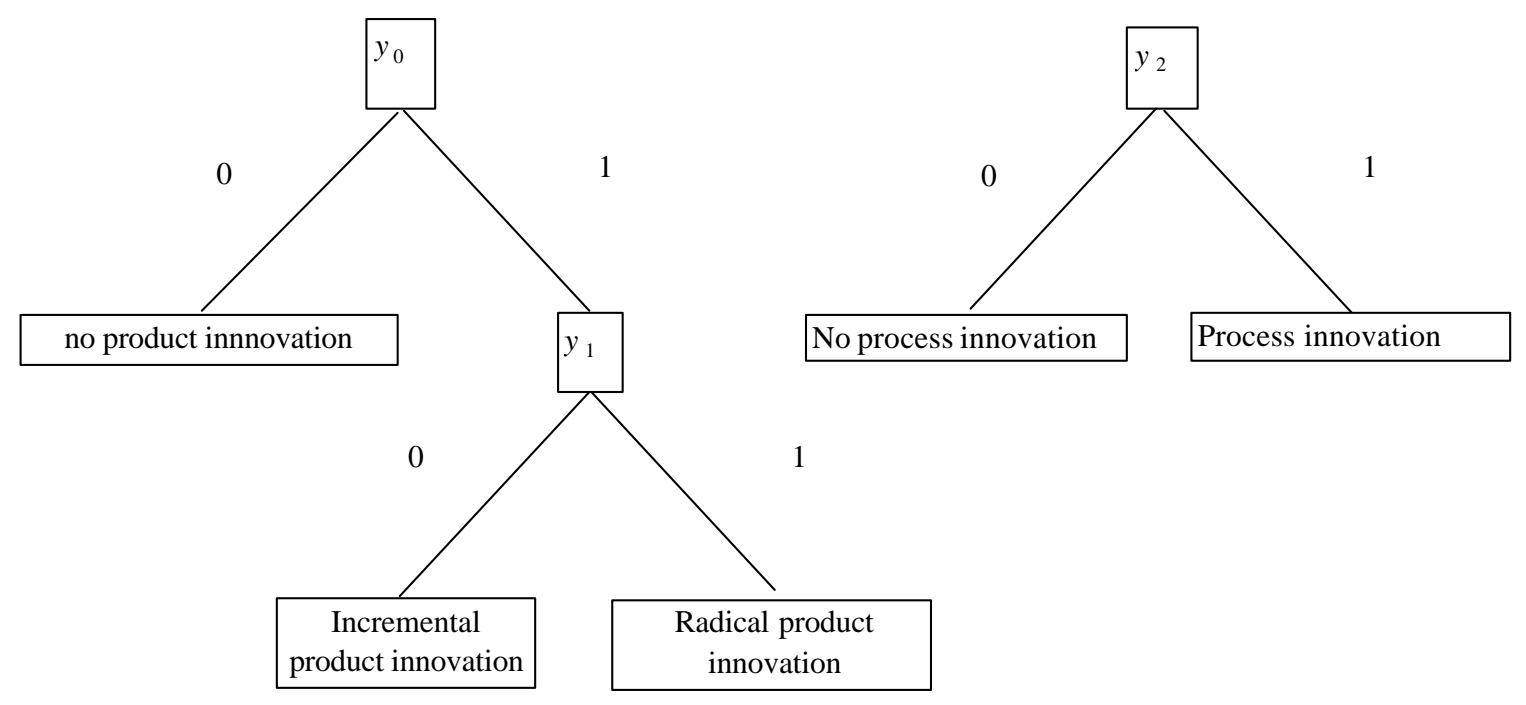

Figure 1 The sequential model

We consider a sample of $n$ observations $(n \in Z)$, indexed by i. To model these different situations, we use three binary variables. Let $\mathrm{y}_{0, \mathrm{i}}=1$ if firm i develops a new product and 0 otherwise. Similarly, we define $\mathrm{y}_{1, \mathrm{i}}=1$ if firm $\mathrm{i}$ introduces a new product technology on the market (radical innovation) and 0 if it imitates an existing product technology (this can be also viewed as a catching up or an incremental innovation). Finally, let $y_{2, i}=1$ if the firm develops a process innovation and 0 otherwise. For instance, a firm does not innovate (i.e. modality $\mathrm{a}_{0}$ is observed) if both $\mathrm{y}_{0, \mathrm{i}}=0$ and $\mathrm{y}_{2, \mathrm{i}}=0$ The sequential model is illustrated in Figure 1.

We assume that the innovation process can be modeled by three continuous latent variable: $\mathrm{w}_{0, \mathrm{j}}, \mathrm{w}_{1, \mathrm{i}}, \mathrm{w}_{2, \mathrm{i}} \in \mathrm{R}$. Let $\mathrm{n}_{0}=\sum_{\mathrm{i}}\left(1-\mathrm{y}_{0, \mathrm{i}}\right)$ denote the number of firms that did not develop a product innovation and $\mathrm{n}_{1}=\sum_{\mathrm{i}} \mathrm{y}_{0, \mathrm{i}}$ denote the number of observations in the second stage with $\mathrm{n}_{0}+\mathrm{n}_{1}=\mathrm{n}$. We first define $\mathrm{w}_{0, \mathrm{i}}$ such that:

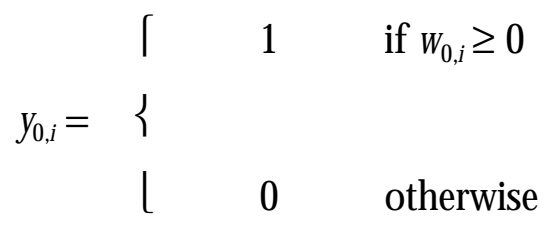

for $i$ from 1 to $n_{0}$. The main feature of the sequential model is that we only observe the variables of the second stage for a subset of observations such that $\mathrm{y}_{0, i}=1$. This corresponds 
to firms that have developed a new product technology. The degree of novelty of the new product technology is also modeled by a continuous latent variable $\mathrm{w}_{1,1}$. For notional convenience, we assume that data have been sorted according to the values of $\mathrm{y}_{0, \mathrm{i}}(\mathrm{i}=1, \ldots$, n). In the second stage, conditionally on $\mathrm{y}_{0, \mathrm{i}}=1$, we define:

$$
\mathrm{y}_{1, i}= \begin{cases} & 1 \text { if } \mathrm{w}_{1, \mathrm{i}} \geq 0 \\ & 0 \text { otherwise }\end{cases}
$$

Finally, we also associate with a process innovation a latent variable $\mathrm{w}_{2, \mathrm{i}}$ such that

$$
y_{2, i}=\left\{\begin{array}{ccc}
1 & 1 & \text { if } \mathrm{w}_{2, i} \geq 0 \\
1 & 0 & \text { otherwise }
\end{array}\right.
$$

We model the latent variables as follows, for $\mathrm{i}=1, \ldots, \mathrm{n}$ and $\mathrm{h}=\mathrm{n}_{0}+1, \ldots, \mathrm{n}$ :

$$
\begin{aligned}
& \mathrm{w}_{0, \mathrm{i}}=\mathrm{x}_{0, \mathrm{i}}{ }^{\prime} \beta_{0}+\varepsilon_{0, \mathrm{i}} \\
& \mathrm{w}_{1, \mathrm{~h}}=\mathrm{x}_{1, \mathrm{~h}}{ }^{\prime} \beta_{1}+\varepsilon_{1, \mathrm{~h}} \\
& \mathrm{w}_{2, \mathrm{i}}=\mathrm{x}_{2, \mathrm{i}}{ }^{\prime} \beta_{2}+\varepsilon_{2, \mathrm{i}}
\end{aligned}
$$

where $\mathrm{x}_{0, \mathrm{i}}, \mathrm{x}_{1, \mathrm{i}}$ and $\mathrm{x}_{2, \mathrm{i}}$ are vectors of explanatory variables of respective dimension $\mathrm{k}_{0}, \mathrm{k}_{1}$ and $k_{2}, \beta_{0}, \beta_{1}, \beta_{2}$ are vectors of parameters to be estimated of respective dimensions $k_{0}, k_{1}$ and $\mathrm{k}_{2}$, and $\varepsilon_{\mathrm{j}, \mathrm{i}}$ are unobservable random variables, for $\mathrm{j}=0,1,2$ and $\mathrm{i}=1, \ldots, \mathrm{n}$.

We assume that the unobservable vector of variables $\left(\varepsilon_{0, h}, \varepsilon_{1, h}, \varepsilon_{2, h}\right)^{\prime}\left(h=n_{0}+1, \ldots, n\right)$ are independently and normally distributed with mean $(0,0,0)^{\prime}$ and covariance

$$
\Sigma=\begin{array}{lllll}
\lceil & \sigma_{0} & \rho_{01} & \rho_{02} & \rceil \\
& \rho_{01} & \sigma_{1} & \rho_{12} & \mid \\
& \rho_{02} & \rho_{12} & \sigma_{2} & \rfloor
\end{array}
$$

where $\sigma_{0}, \sigma_{1}, \sigma_{2}$ denote the variances of the unobservable variables at each stage and $\rho_{01}, \rho_{02}$, $\rho_{12} \in(-1 ; 1)$ represent the covariance between the unobservable variables. In the first stage, 
we do not observe $\mathrm{w}_{1}$, but we still assume that unobservable variables $\left(\varepsilon_{0, i}, \varepsilon_{2, i}\right)^{\prime}\left(\mathrm{i}=1, \ldots, \mathrm{n}_{0}\right)$ have covariance matrix (5) without the central row and column.

Two remarks are in order. First, we note that when $\Sigma$ is diagonal, all latent variables are independent and the coefficients of the model can be estimated by three standard probit regressions. Second, it is clear, from equations (1) - (3), that multiplying each latent equation by a positive constant does not affect the qualitative variables $\mathrm{y}_{0}, \mathrm{y}_{1}$ or $\mathrm{y}_{2}$. Hence, we can not identify both location and scale parameters of these equations. Therefore, we need to impose three restrictions. We have restricted $\sigma_{1}=\sigma_{2}=\sigma_{3}=1$ in (5) so that coefficients $\rho_{01}, \rho_{02}, \rho_{12}$ have the natural interpretation of correlation coefficients. ${ }^{15}$

The correlations between unobservable variables of each stage raise a numerical problem due to multiple integrals that appear in the likelihood function. These integrals correspond to the probability to observe a particular choice by a firm. Indeed, we have for instance:

$$
\begin{aligned}
& \mathrm{p}\left(\mathrm{a}_{0, \mathrm{i}}\right)=\mathrm{p}_{0}=\mathrm{p}\left(\mathrm{y}_{0, \mathrm{i}}=0, \mathrm{y}_{2, \mathrm{i}}=0\right)=\mathrm{p}\left(\varepsilon_{0, \mathrm{i}} \leq-\mathrm{x}_{0, \mathrm{i}}{ }^{\prime} \beta_{0}, \varepsilon_{2, \mathrm{i}} \leq-\mathrm{x}_{2, \mathrm{i}}{ }^{\prime} \beta_{2}\right) \text { and } \\
& \mathrm{p}\left(\mathrm{a}_{5, \mathrm{i}}\right)=\mathrm{p}_{5, \mathrm{i}}=\mathrm{p}\left(\varepsilon_{0, \mathrm{i}}>-\mathrm{x}_{0, \mathrm{i}}{ }^{\prime} \beta_{0,}, \varepsilon_{1, \mathrm{i}}>-\mathrm{x}_{1, i}^{\prime} \beta_{1}, \varepsilon_{2, \mathrm{i}}>-\mathrm{x}_{2, i}^{\prime} \beta_{2}\right)
\end{aligned}
$$

and so on. Since unobservable variables are independent between observations, the loglikelihood function is:

$$
\mathrm{L}=\sum_{\mathrm{i}} \sum_{\mathrm{j}} \mathrm{y}_{\mathrm{j}, \mathrm{i}} \log \left(\mathrm{p}_{\mathrm{j}, \mathrm{i}}\right) \quad(\mathrm{i}=1, \ldots, \mathrm{n}, \mathrm{j}=0, \ldots, \mathrm{J})
$$

where $J=5$ and $1_{\mathrm{j}, \mathrm{i}}$ is equal to 1 for modality $\mathrm{j}$ and 0 otherwise. Waelbroeck (2002) compares the performance of simulated maximum likelihood and Bayesian MCMC methods in the sequential probit model. He concludes that even though both methods yield precise

\footnotetext{
${ }^{15} \mathrm{~A}$ more subtle identification problem arises when different explanatory variables are used at different stages of the survey. In this case, it has to be checked that we estimate the correlation between the unobservable variables and not between an unobservable variable and some explanatory variables of another equation. This was checked in the application by estimating parameters of the model with the same set of explanatory variables. Because the extra set of explanatory variables only includes binary variables, we found that the correlation structure was identical with or without the same set of explanatory variables.
} 
estimates, with a large number of observations and of explanatory variables, the Bayesian method converges faster.

The main focus of the study is equation (4b), which explains the nature of the innovation by the information sources used in the innovation process and the extent of collaboration between innovative firms and other public and private agents, controlling for size and industry differences. Coefficients associated with the sources of collaboration capture all types of knowledge flows through market mechanism. Similarly, coefficients associated with the information sources capture the extent of spillovers accruing to the innovative firm, since we already have controlled for market transfer. A positive (negative) coefficient indicates that the information sources/ collaboration determines how innovative the firm is. Coefficients that are not significantly different from zero reflect the fact that the associated variables can not discriminate between firms that launch radical innovations and firms that imitate existing technologies. There are two possible interpretations: either the information source is necessary for both modes of innovation, or the information is not necessary at all. O ur model can not discriminate between these two interpretations, although looking directly at the data generally gives a good idea of which interpretation prevails.

\section{Results}

Results of the estimation procedure are shown in Table 3. Estimated coefficients that are significantly different from zero are marked by asterisks. Equations (4a)-(4c) include firm size, market power and diversification level as well as three industry dummies. In addition, equation (4b) includes information and cooperation sources. ${ }^{16}$ In table 3, the last two columns gives the parameters of the three equations estimated by three separate independent probit (assuming no correlation between the unobservable variables). ${ }^{17}$

\footnotetext{
16 Parameters associated with variables also present in equation (4a) are identified because they are estimated from a different sample. This is easy to see, when there is no correlation between the unobservable variables of the different equations. In this case, the model can be estimated by three separate regressions.

${ }^{17}$ Results obtained by jointly estimating the three equations using the Bayesian method of Waelbroeck (2002) provide similar results. This is in large part due to the fact that there is little correlation between the unobserved variables of equations (4a) and (4b) and between those of equations (4b) and (4c). We found a strong
} 


\section{Table 3. Estimation results}

\begin{tabular}{|c|c|c|}
\hline Equation (4a): New Product & coefficient & s.e. \\
\hline Constant & $-4.5037^{* * *}$ & 0.2434 \\
\hline Market power & 0.0450 & 0.0442 \\
\hline Diversification & 0.0723 & 0.0920 \\
\hline Size & 0.3539 & 0.0227 \\
\hline Car sector & $0.4416^{* * *}$ & 0.1358 \\
\hline Equipment good sector & $0.7081^{* * *}$ & 0.0695 \\
\hline Intermediate good sector & \multirow[t]{2}{*}{$0.4349^{* * *}$} & \multirow[t]{2}{*}{0.0600} \\
\hline Number of obs. $=3193, \chi^{2}=680.4(p-v$ & & \\
\hline Equation (4b): D egree of Novelty & coefficient & s.e. \\
\hline Constant & $-0.7472^{* * *}$ & 0.2855 \\
\hline Market power & -0.0213 & 0.0376 \\
\hline Diversification & 0.0726 & 0.0835 \\
\hline Size & 0.0347 & 0.0247 \\
\hline Car sector & -0.1238 & 0.1280 \\
\hline Equipment good sector & 0.1211 & 0.0748 \\
\hline Intermediate good sector & $0.1523^{* *}$ & 0.0674 \\
\hline \multicolumn{3}{|l|}{ Information sourœes: low intensity level } \\
\hline Internal sources & 0.0841 & 0.1295 \\
\hline Other firms of the group & 0.0203 & 0.0721 \\
\hline Competitors & $-0.1275^{*}$ & 0.0693 \\
\hline Customers & -0.1359 & 0.0885 \\
\hline Suppliers of equipment and software & 0.0620 & 0.0665 \\
\hline Suppliers of components and raw mat. & 0.0640 & 0.0678 \\
\hline Consulting market research firms & 0.0517 & 0.0651 \\
\hline Universities or establish. of higher edu. & -0.0732 & 0.0670 \\
\hline Public and non-profit research org. & -0.0298 & 0.0729 \\
\hline Publications of patents & $0.2624^{* * *}$ & 0.0685 \\
\hline Technical journals and conferences & 0.0892 & 0.0692 \\
\hline Fairs and exhibitions & $0.1761^{* *}$ & 0.0735 \\
\hline \multicolumn{3}{|c|}{ Information souroes: average intensity level } \\
\hline Internal sources & 0.0260 & 0.1110 \\
\hline Other firms of the group & -0.0473 & 0.0686 \\
\hline
\end{tabular}

correlation (about 80\%) between unobservable variables of equations (4a) and (4c), but this does not affect the estimated parameters in equation (4b). 


\begin{tabular}{|c|c|c|}
\hline Competitors & $-0.2295^{* *}$ & 0.0707 \\
\hline Customers & -0.0126 & 0.0819 \\
\hline Suppliers of equipment and software & 0.0573 & 0.0693 \\
\hline Suppliers of components and raw mat. & -0.0239 & 0.0714 \\
\hline Consulting market research firms & 0.0299 & 0.1009 \\
\hline Universities or establish. of higher edu. & -0.0588 & 0.0897 \\
\hline Public and non-profit research org. & -0.0028 & 0.0980 \\
\hline Publications of patents & $0.3584^{* * *}$ & 0.0815 \\
\hline Technical journals and conferences & 0.0211 & 0.0738 \\
\hline Fairs and exhibitions & $0.1513^{* *}$ & 0.0724 \\
\hline \multicolumn{3}{|c|}{ Information sources: high intensity level } \\
\hline Internal sources & 0.0619 & 0.1062 \\
\hline Other firms of the group & $0.2830^{* * *}$ & 0.0761 \\
\hline Competitors & $-0.2176^{* *}$ & 0.0941 \\
\hline Customers & $0.2364^{* * *}$ & 0.0853 \\
\hline Suppliers of equipment and software & -0.0298 & 0.0910 \\
\hline Suppliers of components and raw mat. & $0.3300^{* * *}$ & 0.0962 \\
\hline Consulting market research firms & $0.4398^{* *}$ & 0.2237 \\
\hline Universities or establish. of higher edu. & $-0.2590^{*}$ & 0.1469 \\
\hline Public and non-profit research org. & $-0.3529^{* *}$ & 0.1621 \\
\hline Publications of patents & $0.4708^{* * *}$ & 0.1283 \\
\hline Technical journals and conferences & -0.0984 & 0.1326 \\
\hline Fairs and exhibitions & $0.6052^{* * *}$ & 0.1038 \\
\hline \multicolumn{3}{|l|}{ D omestic C ollaboration } \\
\hline Other firms of the group & 0.0286 & 0.0767 \\
\hline Competitors & -0.0138 & 0.1473 \\
\hline Customers & 0.0341 & 0.0755 \\
\hline Suppliers of equipment and software & $0.3305^{* * *}$ & 0.0939 \\
\hline Suppliers of components and raw mat. & 0.0495 & 0.0823 \\
\hline Consulting market research firms & 0.0461 & 0.1127 \\
\hline Universities or establish. of higher edu. & $-0.1422^{*}$ & 0.0834 \\
\hline Public and non-profit research org. & -0.1002 & 0.0901 \\
\hline \multicolumn{3}{|l|}{ International collaboration: $\mathrm{E} \mathrm{U}$} \\
\hline Other firms of the group & 0.1287 & 0.0789 \\
\hline Competitors & 0.0439 & 0.1364 \\
\hline Customers & 0.0658 & 0.1014 \\
\hline Suppliers of equipment and software & $-0.4170^{* * *}$ & 0.1164 \\
\hline Suppliers of components and raw mat. & 0.0558 & 0.0946 \\
\hline Consulting market research firms & 0.3597 & 0.2194 \\
\hline
\end{tabular}




\begin{tabular}{|c|c|c|}
\hline Universities or establish. of higher edu. & $0.4208^{* * *}$ & 0.1525 \\
\hline Public and non-profit research org. & $0.3645^{*}$ & 0.2186 \\
\hline \multicolumn{3}{|l|}{ International Collaboration: U SA } \\
\hline Other firms of the group & -0.0050 & 0.0930 \\
\hline Competitors & $-0.3582^{*}$ & 0.1846 \\
\hline Customers & 0.2378 & 0.1460 \\
\hline Suppliers of equipment and software & 0.1852 & 0.1630 \\
\hline Suppliers of components and raw mat. & -0.1506 & 0.1549 \\
\hline Consulting market research firms & $-1.0549^{* * *}$ & 0.2962 \\
\hline Universities or establish. of higher edu. & 0.2248 & 0.2510 \\
\hline Public and non-profit research org. & $-0.7677^{*}$ & 0.3976 \\
\hline \multicolumn{3}{|l|}{ Number of obs. $=1460, \chi^{2}=149.2(p$-value $<.005)$} \\
\hline Equation (4c): Process Innovation & coefficient & s.e. \\
\hline Constant & $-4.0597^{* * *}$ & 0.2370 \\
\hline Market power & -0.0184 & 0.0422 \\
\hline Diversification & -0.0403 & 0.0893 \\
\hline Size & $0.3139^{* * *}$ & 0.0221 \\
\hline Car sector & $0.3684^{* * *}$ & 0.1327 \\
\hline Equipment good sector & $0.4232^{* * *}$ & 0.0685 \\
\hline Intermediate good sector & $0.3170^{* * *}$ & 0.0594 \\
\hline Number of obs. $=3193, \chi^{2}=485.2(p-$ value $<0.005)$ & & \\
\hline
\end{tabular}

First, estimation results suggest that most benefits from contacts with universities and public research organizations arise from formal collaboration. On the one hand, there is little evidence of direct spillovers from universities (this is confirmed by the low percentage of firms having declared using information from universities in Table 1). It appears that the magnitudes of these externalities are much smaller than other types of spillovers, such as spillovers from customers and suppliers. Moreover, we find some evidence that these spillovers are strongest among firms that imitate existing technologies. One the other hand, we find convincing evidence that highly innovative firms engage in formal cooperation with European universities. Cooperation with domestic universities has no such effect. Indeed, highly innovative firms are at the frontier of the domestic academic knowledge in their industry and have state of-the-art research department. Therefore, they only marginally benefit from aggregate (or industry-wide) spillovers from domestic universities. They need 
new forms of academic knowledge that they acquire through formal cooperation with foreign universities. On the contrary, firms that attempting to catching-up to the most innovative companies benefits the most from state of the art knowledge generated by academic scientists. This interpretation is also consistent with the fact that marginal benefits can arise from dissemination of knowledge at the industry level. ${ }^{18}$

O ur findings are similar to those obtained in the literature. First, Cohen et al. (2002) analyze the channels of knowledge transfers between public research organizations and innovative firms and find that universities can have two different roles: suggesting new ideas and helping completing existing projects. They find that universities are less important than other industrial agents in the innovation process. Their data also suggests that the most important sources of spillovers are informal meetings, publications and conferences. By explicitly the degree of novelty of the innovation, we obtained an additional very intuitive result: intra-industry spillovers (information from competitors) are important for firms that imitate existing product technologies. Second, arr result that formal collaboration is not nationally confined is consistent with the study of Audretsch and Stephan (1996). Finally, we conjecture that geographically close collaborations between firms and universities are important for staying at the state-of-the-art in a given industry, and thus proximity might be important for incremental innovation and technological imitation. Indeed, licenses analyzed by Mowery and Ziedonis (2001) can be, arguably, associated with firms that lack a state-of-theart research department. However, we need a much more detailed geographical analysis to test this hypothesis. ${ }^{19}$

\section{Conclusion}

The fact that international collaboration between universities and firms increases their innovative performance suggests that economic policies that promote the internationalization of knowledge flows should be strongly promoted in Europe. This also

\footnotetext{
${ }^{18}$ It is worth noting that the individual characteristics of the firm and the industry in which they operate are less important than the information sources they used and the type of collaborative agreements they have with other partners. For this reason, we do not believe that our results are driven by unobserved heterogeneity at the firm level.
} 
suggests that there is no complete market failure of the appropriation of university research and that academic knowledge is complementary to industry research. However, we found evidence that spillovers are important for firms that are catching up a technological gap, so that relying on a complete market mechanism to finance university research could harm the innovation process at the aggregate level. The evidence found in the estimation results should of course be replicated in other countries and over different period of time.

\section{References}

Appleyard, M. M., 1996, "How Does Knowledge Flow? Interfirm Patterns in the Semiconductor Industry," Strategic M anagement Journal, 17, 137-154.

Audretsch, D. B., and Stephan, P. E., 1996, "Company-Scientist Locational Links: The Case of Biotechnology," A merican E conomic Review, 86, 641-652.

Berman, E. M., 1990, "The Economic Impact of Industry-funded University R\&D", Research Policy, 19, 349-355.

Cohen, W. M., and Levinthal, D. A., 1989, "Innovation and Learning: The Two Faces of R\&D," E conomic Journal, 99, 569-596.

Cohen, W. M., and Walsh, J. P., 2000, "R\&D Spillovers, Appropriability and R\&D Intensity: A Survey Based Approach", M imeo, Carnegie Mellon University.

Cohen, W. M., Nelson, R. R, and Walsh, J. P., 2002, "Links and Impacts: The Influence Public Research on Industrial R\&D," M anagement Science, 48, 1-23.

Dasgupta, P. and P. D avid, 1999, "Towards a New Economics of Science," Research Policy, 23, 487-521.

François J.-P and F. Favre, 1998, L'innovation technologique progresse dans l'industrie. L es 4 Pages du SE SSI, nº9.

Jaffe, A. B., 1989, "Real Effects of Academic Research", The A merican E conomic Review, 79 (5), 957-970.

${ }^{19}$ A geographical analysis could in principle be done since with have the address and postal code of all firms having answered to the innovation survey. 
Gibbons, M. and R. Johnston, 2000, "The Roles of Science in Technological Innovation," in: Stephan (Ed.), The E conomics of Science and Innovation, Vol. 2, Northampton, MA: Elgar.

Griliches Z., 1990, Patents Statistics as Economic Indicators : a Survey, Journal of E conomic L itterature, 28, 1661-1707.

Griliches, Z., 1992, The Search for R\&D Spillovers, Scandinavian Journal of E conomics, 94, 2947.

Link A. N. and J. Rees, 1990, "Firm Size, University Based Research, and the Returns to R\&D ", Small Business E conomics, 2, 25-32.

Mansfield, E., 1991, "Academic Research and Industrial Innovation", Research Policy, 20, 1-12.

Mansfield, E., 1995, "Academic Research Underlying Industrial Innovations: Sources, Characteristics, and Financing", Review of E conomics and Statistics, 77, 55-65.

Mowery, D. C., and Ziedonis, A. A., 2001, "The Geographical Reach of Market and NonMarket channels of Technology Transfer: Comparing Citations and Licenses of University Patents," N BE R W orking Paper 8568

Poyago-Theotoky, J., Beath, J., Siegel, D .S. (2002), "Universities and Fundamental Research: Reflections on the Growth of University-Industry Partnerships," Ox ford Review of E conomic Policy, 18, 10-21.

Rosenberg, N., and Nelson, R. R., 1994, "American Universities and Technical Advance in Industry", Research Policy, 23, 323-348.

Schrader, S., 1991, "Informal Technology Transfer Between Firms: Cooperation Through Information Trading," Research Policy, 20, 153-170.

Siegel, D .S., Waldman, D. and Link, A.N. (2003), "Assessing the Impact of Organizational Practices on the Relative Prodcutivity of University Technology Transfer Offices: An Exploratory Study," Research Policy, 32, 27-48.

Torero, M., 2000, "Analyzing the Spillover Mechanism on the Semiconductor Industry in the Silicon Valley and Route 128", W orking Paper.

Waelbroeck, P., 2002, "Comparison of Simulated Maximum Likelihood and Bayesian MCMC in the Sequential Probit Model," Mimeo. 
Zucker, L. G., Darby, M. R., and Armstrong, J., 1998, "Geographically Localized Knowledge: Spillovers or Markets?" , E onomic Inquiry, 36, 65-86. 